\title{
Gerónimo Amici y los proyectos de cuarteles para el regimiento de caballería de Andalucía, en la provincia de Huelva
}

\author{
juan Carlos Hernandez
}

El Cuerpo de Ingenieros Militares es una de las instituciones más interesantes de las creadas en la España del siglo XVIII. Fundado por Felipe $V$ en 1711, a imitación de su homónima francesa, tuvo un carácter principalmente militar. Nació como un grupo de técnicos, altamente cualificados al servicio de la Corona, para la defensa del territorio sobre la que ésta gobernaba. Su principal función era la mejora de los sistemas defensivos, pero su labor también llevará a un mejor conocimiento del territorio y sus comunicaciones. Serán los encargados de la construcción y reparación de fortificaciones, canales, caminos y puertos y del levantamiento de planos. A estas actividades se le unirán las derivadas de los intereses económicos y sociales de la Corona, expresadas en la construcción de fábricas y otros edificios de carácter civil y religioso. Muchas de sus ideas quedaron en simples proyectos, pues nunca llegaron a materializarse. A pesar de ello, dichos proyectos son de gran importancia por las consecuencias que tuvieron para el desarrollo de la arquitectura española de la segunda mitad del siglo XVIII y de principios del XIX. Frente al recargamiento del barroco de la época, los ingenieros primarán en sus obras lo funcional y racional, frente a lo ornamental y accesorio, facilitando la difusión del sobrio y severo neoclasicismo.

Son muchos los proyectos de ingenieros militares que existen en los archivos españoles. Así, en el Archivo General de Simancas, en su sección de "Planos, mapas y dibujos" se conserva una colección de diecinueve planos de cuarteles, para el Regimiento de Caballeria de la Costa 
de Andalucía, denominado de Cuantiosos, proyectados para otras tantas localidades de la actual provincia de Huelva '. Fueron realizados por el ingeniero militar Gerónimo Amici, apareciendo fechadas en Sevilla el 4 de marzo de 1740. Dichos planos constan, por lo general, de la planta de las casas destinadas a cuartel, así como de la planta y dos secciones, longitudinal y transversal, de la nueva construcción. Completándolos aparece una pequeña explicación de los mismos. Cada plano, a su vez, se corresponde con un expediente de la sección de "Guerra Moderna", formado por una descripción de los planos y el presupuesto de la nueva construcción, distribuido en diversas partidas ${ }^{2}$. En ocasiones la documentación se completa con la descripción del emplazamiento elegido y los acuerdos de los respectivos cabildos proponiendo las rentas que se destinarían al edificio ${ }^{3}$.

Estos cuarteles vienen a ser una de las consecuencias del conjunto de reformas realizadas por Felipe $V$ para la transformación del ejército. Cuando el monarca francés ocupa el trono español, el ejército se basaba en un sistema de levas inoperantes, por lo cual eran los mercenarios los que venian a formar el grueso de sus filas. Éstos no tenian un alojamiento fijo, sino que se encontraban en campamentos itinerantes, refugiándose en las fortificaciones por las que pasaban o se acomodaban en las casas de los vecinos de las poblaciones en las que acampaban. Ello causaba a los vecinos gran cantidad de problemas, no sólo de orden económico sino también social, por lo que la mayor gracia que un pueblo podía recibir del rey era el estar libre del alojamiento de la milicia.

Ante esta situación, Felipe $V$, imitando lo que ya habia hecho su abuelo en Francia, comienza con la reorganización y reforma del ejército, creando un cuerpo permanente y eficaz, con asentamientos fijos en puntos estratégicos del territorio. Es éste, el de los asentamientos fijos, una de las consecuencias más interesantes de la reforma del ejército, ya que dará origen a una nueva tipología de edificios, los cuarteles.

- Archivo General de Simancas (A.G.S.), Mapas, Planos y Dibujos, XIV, $n .^{\circ 5} 59,60$, 61,62 y $63 ;$ XXVII, n. ${ }^{\text {os }} 65,66,6768,70,71,72$ y $73 ;$ XXVIII, n. ${ }^{\circ} 18$, y XXXVIII, n. ${ }^{\text {os }} 25$ y 27. Las localidades a las que se refieren los diferentes proyectos, continuando la numeración que aparece en los expedientes, son: Moguer, Huelva, Cartaya, Lepe, La Redondela, Ayamonte, Villablanca, San Silvestre de Guzmán, Sanlúcar del Guadiana, Villanueva de los Castillejos, Puebla de Guzmán, Paimogo, Santa Bárbara de Casa, Aroche, Encinasola, Cortegana, Almonaster la Real, El Cerro de Andévalo y Trigueros. Cfr. Álvarez Teran, M. C., "Mapas, Planos y Dibujos. (1503-1805)". Tomo I. Archivo General de Simancas. Catálogo XXIX. Valladolid 1980.

2 A.G.S., Guerra Moderna (G.M.), Leg. 3.673.

3 Esta última parte del expediente falta para los pueblos de Moguer, Ayamonte y Paimogo. 
El cuartel como edificio de alojamiento de la tropa habia sido ya creado por el mariscal francés Vauban para la infantería de ese país, a finales de la centuria anterior. Éste consistia en un edificio rectangular, normalmente adosado a las murallas de una fortificación, que le servia de defensa. En los extremos del mismo eran colocadas las dependencias de los oficiales, mientras las de la tropa se distribuian por la nave central. Éstas constaban de una doble crujia dividida por muros transversales, formando pequeños módulos para diez o doce soldados con acceso directo a la calle. Tales módulos eran repetidos hasta adecuarse al número de los soldados ${ }^{4}$. Siguiendo el mismo modelo del ingeniero catalán, pero de formación francesa, Bernard Forest de Belidor, mejora la idea al concebir cuatro edificios, con la misma disposición de Vauban, en torno a un patio central. Cuando dichos edificios eran aplicados a la caballería, las cuadras se colocaban en planta baja, mientras que en la superior se distribuian los alojamientos de los soldados. La innovación de este edificio es que el cuartel pasa a formar parte de la ciudad, sin la necesidad de construirse cerca o adosados a edificaciones fortificadas ${ }^{5}$.

Sin embargo, el modelo de cuartel más difundido en España sería la versión que del cuartel de Vauban realiza Jorge Próspero Verboom, en su Proyecto General Impreso. Verboom, formado en la Academia Militar de Bruselas, desempeñó el cargo de Ingeniero General en los Países Bajos españoles y colaboró con Vauban en las campañas flamencas durante la Guerra de Sucesión. Procedente de este país llegará a España, llamado por Felipe $V$ para que colaborase con el Secretario del despacho Guerra en 1709. Un año más tarde, será nombrado Ingeniero General de los Ejércitos, Plazas y Fortificaciones de todos los Reinos, Provincias y Estados y Cuartel Maestre General de todos los ejércitos, siendo el encargado de crear el Cuerpo de Ingenieros, aprobado por el rey el 17 de abril de $1711^{6}$.

Verboom redacta el reglamento sobre construcción de cuarteles de nueva planta, conocido con el nombre de Proyecto General Impreso, aprobado por el rey el 8 de abril de $1718^{7}$. En dicho reglamento, se

4 Marzal Martínez, Amparo, "Notas subre arquitectura militar dieciochesca en Andalucia. Cuarteles". I Congreso de Historia de Andalucía. Andalucia Moderna, (siglo XVIII). Córdoba 1978. Tomo II, pág. 4.

Idem, pág. 5 .

6 Sobre la creación del Cuerpo de Ingenieros Militares y la figura de José Próspero Verboom, véase CAPEL, Horacio, SÁnChEZ, Joan Eugeni y MONCADA, Omar: De Palas a Minerva. Madrid-Barcelona 1988, págs. 14-32.

Marzal Martinez, Amparo, Op. cit., pág. 4. Un comentario más extenso aparece en BONEt CORREA, Antonio, Fiesta, poder y arquitectura. Aproximaciones al barroco español. Madrid 1990, pág. 102-103. 
daban las trazas del modelo de cuartel que se debería construir en todas las provincias españolas. Éstas se completaban con un plano diseñado por el ingeniero ordinario Felipe Pallota y grabada por Juan Bernabé Palomino, constando de planta, alzado, varias secciones y perfiles ${ }^{8}$. El cuartel propuesto por Verboom era el de Vauban, integrado por un gran cuerpo central con dos plantas, distribuidas según los módulos del francés, donde al centro se marcaría la entrada principal bajo un frontón, cubriéndose el edificio a dos aguas. En los extremos, se ubicaban los pabellones de los oficiales, dispuestos en tres plantas y cubiertos a cuatro aguas. Si bien, este modelo era el dedicado a la infantería, se repetia para caballería, pero añadiendo en sus traseras diversas naves, destinadas a caballerizas, formando al enlazar con aquel una serie de patios. No sólo su estructura era copiada del modelo francés, sino que todos los detalles del edificio venian a ser un reflejo de la arquitectura clasicista del país vecino.

A pesar de la gran difusión que tuvo dicho Proyecto General, ya que fue enviado a todas las provincias donde se deberian construir cuarteles de nueva planta, no pensamos que tuviese una gran repercusión, pues presentaba una serie de inconvenientes derivados de problemas de seguridad, de higiene y de espacio. Más tarde, en la segunda mitad del siglo, Miguel Sánchez Taramas los analizará detalladamente al traducir y comentar el Tratado de fortificación de Juan Müler ${ }^{9}$. Taramas al comentar el modelo que presenta Müler, que no es otro que el de Vauban, señala que "este género de Cuarteles son incómodos para la tropa, impropios para lograr la mejor disciplina y costosos sobremanera, por los muchos muros de división y piezas que se desperdician en inútil número de escaleras" " ${ }^{10}$. Seguía el discurso de Taramas aludiendo a que el espacio perdido en las escaleras venía a ser una cuarta parte de la superficie total del edificio. Además, indicaba que el gran número de accesos desde la calle, hacia dificil su control y vigilancia, y que, las cocinas y servicios deberian construirse fuera del "Cuerpo de Cuarteles" para evitar los inconvenientes derivados de tales dependencias. En este sentido, hay que añadir, que para estas fechas, el problema del espacio se habia agravado aún más, al entrar en vigor el 4 de octubre de 1766 el Real

B Bonet Correa, Antonio, Op. cit., pág. 102.

9 Mülef, Juan. Tratado de fortificación, o Arte de construir los edificios militares y civiles. Traducido por Miguel Sánchez Taramas. Barcelona 1769.

10 Idem, págs. 375-376. No somos de la opinión de Marzal, cuando dice que la traducción que realiza Taramas del tratado de Müler sirvió para la difusión del modelo de Vauban y Belidor, ya que el traductor hace una dura crítica del modelo y propone otro como alternativa. Marzal Martinez, Amparo, Op. cit., pág. 5. 
Decreto por el que se estipulaba que hubiese una cama por cada hombre, y no que cada cama fuera ocupada por dos o tres soldados, como era habitual. Intentando dar una solución definitiva, Taramas aboga por el modelo de cuarteles que se acababan de construir en Reus y en Barcelona, de infantería y caballeria, respectivamente ${ }^{1 "}$. Este último se organiza en un edificio rectangular de dos plantas con cubierta a dos aguas y patio central. Solamente se explica la distribución de la planta baja, refiriéndose a la alta como dormitorios en general. Cada lado mayor del rectángulo está dividido en tres partes, de las cuales las caballerizas ocupaban los extremos. En la zona central se sitúan las puertas de acceso y los pasillos que conducen al patio. A los lados de éste, en la fachada principal, estarían las dependencias del cuerpo de guardia, el del oficial de Piquete y la prisión. En la fachada trasera se localizan las habitaciones del veterinario, la del herrador y la del vivandero. Al centro de los lados menores se colocan las escaleras de subida a los dormitorios, quedando a sus lados las cocinas, el almacén de la paja, los retretes y las caballerizas, una para los caballos enfermos y otra para los de los oficiales. La explicación de la planta alta queda reducida a "dormitorios en general», lo que hace suponer la existencia de grandes salas intercomunicadas. Por otra parte y aunque nada dice la descripción, debe considerarse, que en esta planta se situarían las habitaciones de los oficiales, siendo lo más normal que tuvieran un acceso distinto al de la tropa, por lo que posiblemente una escalera de las dos del patio, tuviera tal cometido.

El tipo de edificio propuesto por Taramas no es una auténtica invención, puesto que recoge las propuestas que se habian ido ofreciendo durante la primera mitad del siglo. Aquellas darían como resultado un nuevo modelo, que conviviría con el del Proyecto General Impreso, como se advierte en ocho de los cuarteles construidos en Andalucía entre 1732 y $1743^{12}$. Con respecto a los cuarteles proyectados por Gerónimo Amici para el Regimiento de Caballería de Andalucia, es evidente que ofrecen más puntos de conexión con el proyecto de Taramas que con el de Verboom.

Al analizar los dibujos de los cuarteles de Amici hay que tener presente una serie de factores condicionantes de sus plantas y distribución.

11 Müler, Juan, Op. cit., págs. 376 y ss.

12 Éstos han sido estudiados por Marzal Martínez, Amparo, Op. cit. Un estudio mucho más profundo del cuartel proyectado en la ciudad de Arcos ha sido realizado por BAENA GallÉ, José Manuel, “Bartolomé de Amphoux: Proyecto de cuartel y puente para Arcos de la Frontera". Jornadas Nacionales: La ingeniería militar en la cultura artística española. Cadiz, noviembre de 1989. En prensa. 
En primer lugar, la capacidad máxima de éstos es la de una compañia, cincuenta caballos, y no la de un regimiento, como ocurre en los anteriormente aludidos. En segundo término, debe considerarse que al proyectarse en el interior de centros urbanos deben acomodarse al espacio existente, respetando las alineaciones de calles y la configuración de los edificios circundantes. Es más, en algunas ocasiones, incluso se reaprovechan estructuras precedentes. Así, el cuartel proyectado para Villanueva de los Castillejos se encontraba situado en el centro del pueblo, presentando medianera con la iglesia parroquial. En otros pueblos, como Encinasola y Cartaya, el proyecto se acomodó a las fortificaciones existentes en las localidades y que se encontraban abandonadas. Finalmente, el tercer factor a evaluar es el adecuado acomodo de los oficiales, según su graduación, que se encontraban al cargo de la tropa en cada cuartel. Por ello, el cuartel de mayor envergadura será el de Moguer, en el que radicaba el mando del Regimiento.

Con respecto al plano de Verboom, los cuarteles de Amici presentan algunas novedades. El número de accesos queda reducido en los edificios de una sola planta, a un máximo de tres, uno para las caballerizas, otro para la tropa y el tercero para los oficiales. El Cuerpo de Guardia se coloca indistintamente en la entrada de la tropa o de las caballerizas. Cuando el edificio es de dos plantas, los accesos son dos, uno para los oficiales y otro para la tropa o las caballerizas. Las escaleras, en estos últimos edificios queda reducida a la de servicio de la tropa, o se duplican si el dormitorio de ésta se encuentra repartido en distintas salas inconexas. Para las escaleras de los oficiales, su número varia según la distribución de sus dependencias en el edificio. Las cuadras, cuando el edificio es de una sola planta, se encuentran frente al dormitorio de la tropa, separadas por el patio, o lo más cercanas a éste. Cuando el cuartel tiene dos plantas, aquellas se sitúan bajo el dormitorio. En ambos casos, dichas dependencias presentan la misma estructura o parecida distribución. De todas formas, las cuadras forman parte del edificio del cuartel y no se presentan en edificaciones anexas, como sucede con el proyecto de Verboom. Tanto las cocinas como los servicios de la tropa se sitúan en los extremos de los dormitorios, en los ángulos del edificio, con ventilación hacia la calle o el patio.

En algunos proyectos, las dependencias de los oficiales, conforme al esquema de Verboom, ocupan los extremos del edificio, aunque es mucho más habitual, en razón del número de los mismos, colocarlos en los espacios vacios entre la tropa y las caballerizas. Dependiendo de la graduación, ocupan los mejores lugares en fachada o en segunda planta.

Los edificios se cubren con tejados a dos aguas, excepto las zonas 


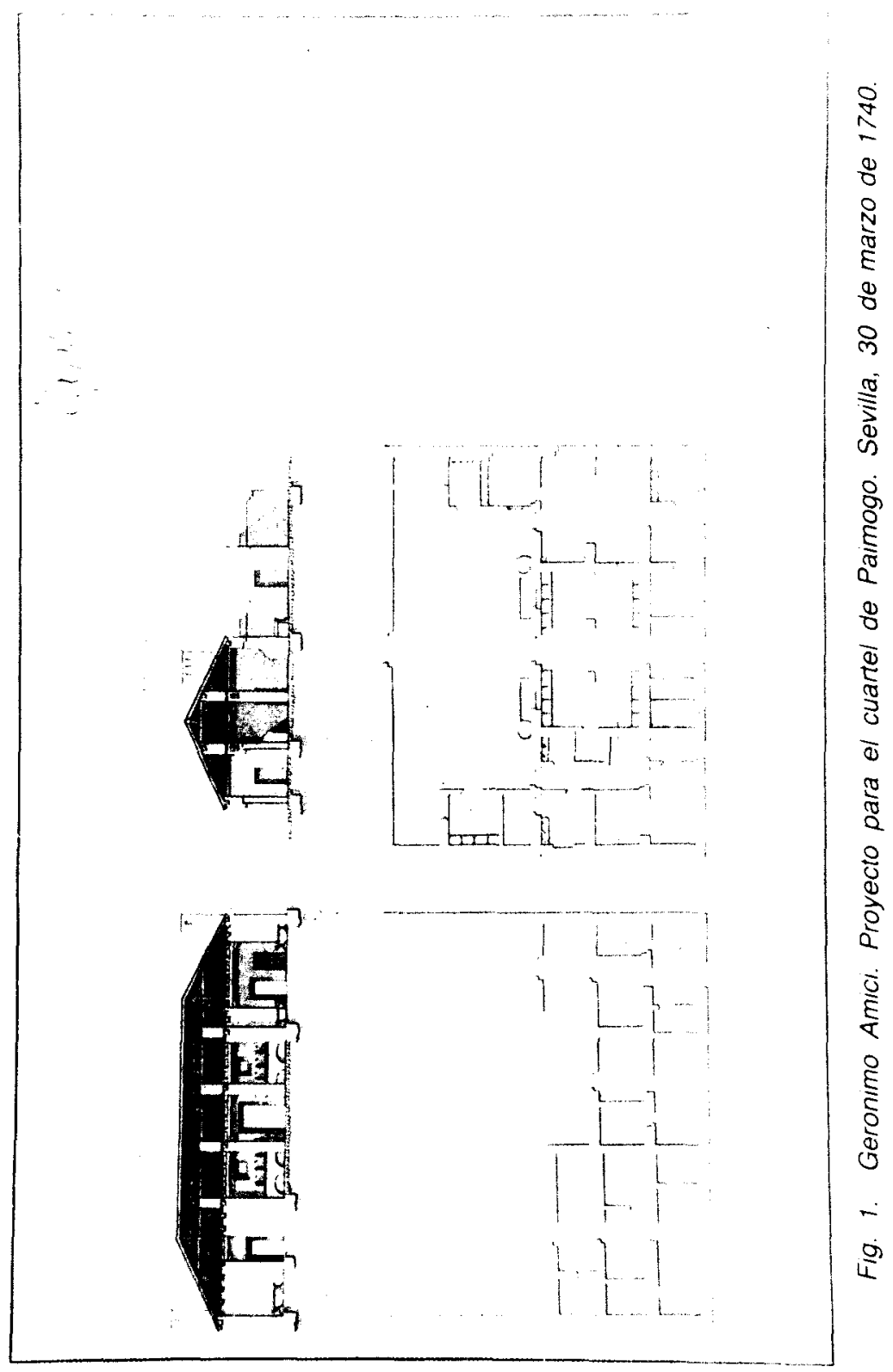


de una sola crujia que lo hará a un agua. Aquellos no presentan las buhardillas de ventilación que aparece en el Proyecto General. Interiormente, los techos son siempre planos, formándose con viguería de madera. Sin embargo se seguirá el proyecto de Verboom, en la configuración de puertas exteriores y ventanas, siendo rectangulares con las jambas en derrame. Sólo para el interior, la comunicación entre las crujías puede realizarse mediante arcos de medio punto.

A pesar de que en ningún proyecto se recoge alzado de la fachada, atendiendo a las secciones donde aparece algún frente de los patios, se puede afirmar que Amici sigue los ideales de Verboom de severidad y solidez, aunque los materiales queden reducidos al ladrillo y a la mampostería y no se utilice la alternancia con la piedra, como proponía el último. Como recomendaba Verboom, los motivos decorativos quedan reducidos a frisos que, a modo de cornisas, sirven para separar las plantas, a los zócalos en planta baja y alta, y a las bandas que enmarcan las ventanas y las puertas. En algunas ocasiones, dichas bandas continúan verticalmente hasta unirse con las cornisas y los zócalos. Solamente en las secciones de los cuarteles proyectados para Encinasola y Cartaya se recoge el acceso principal al edificio de doble altura que ocupa el frente del patio. En aquel se enmarca por pilastras o columnas toscanas y en éste se dispone sobre la puerta un frontón curvo y roto, destinado a albergar un escudo.

Para estudiar los proyectos de las diecinueve poblaciones onubenses se han establecido tres grupos, atendiendo a su distribución en una o dos plantas. En ambos se han fijado subgrupos según exista o no el patio y su ubicación. El primer grupo está compuesto por edificios de planta rectangular y un solo piso. Dentro de éste, el subgrupo más numeroso es el que presenta un patio trasero rectangular, como ocurre en los proyectos para las poblaciones de La Redondela, San Silvestre de Guzmán, Puebla de Guzmán y Paimogo. Estos edificios se encuentran distribuidos en dos o tres crujias, divididas en tres módulos sin comunicación entre ellas. En el central se coloca la entrada principal, el cuerpo de Guardia y las caballerizas, comunicadas con el patio. En uno de los laterales con acceso a la calle y al patio, se localizan el dormitorio de la tropa, en una sola estancia, con los retretes, la cocina y el cuarto del sargento. En el otro figuran la casa del oficial, con sus respectivos servicios y caballería. En el caso de Paimogo y La Redondela, la cocina, letrinas y caballerizas para oficiales se distribuyen por los lados menores del patio. En la última de estas poblaciones, el acceso desde el patio a las dos primeras dependencias se realiza bajo un pórtico adintelado, existiendo además una cuadra para caballos enfermos, frente a la de los 


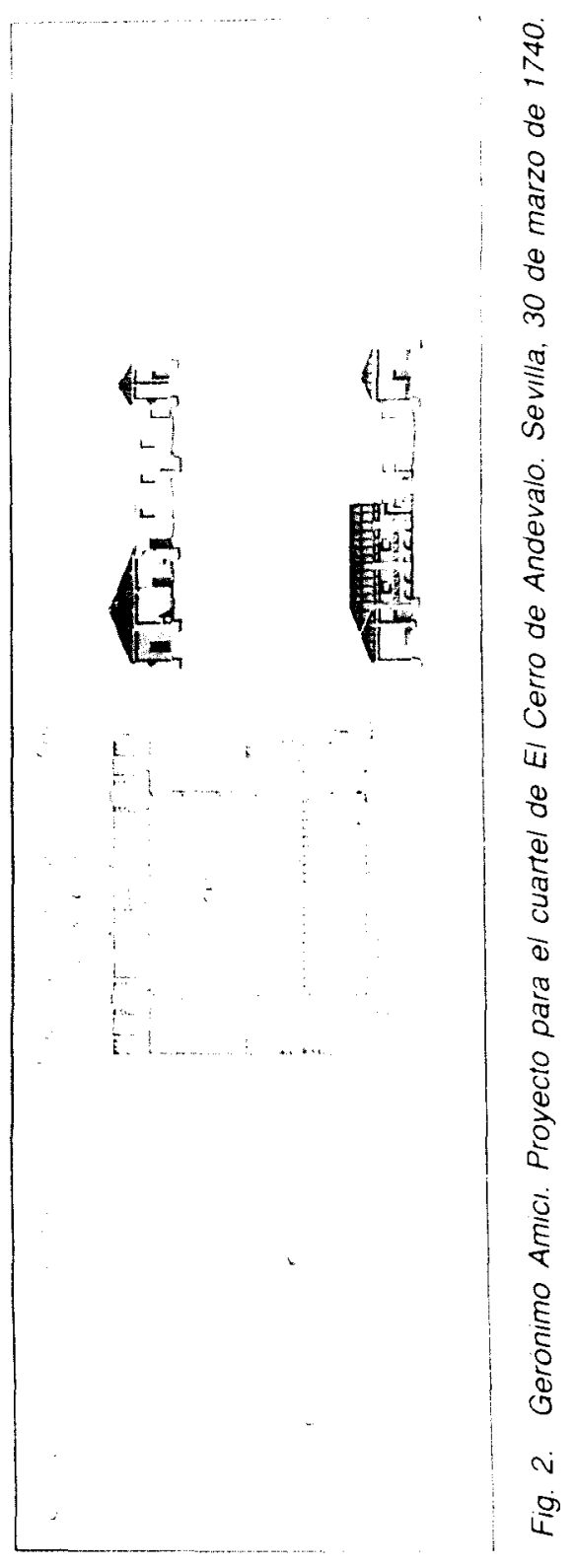


oficiales. En general, el patio está configurado por un simple muro de cerramiento, abriéndose en el centro de su lado mayor una puerta a la calle.

El segundo subgrupo, formado por los cuarteles de Villablanca, Cortegana y el Cerro del Andévalo, presentan un edificio rectangular de una sola planta, en torno a un patio central. Su distribución varía de un cuartel a otro. En el de Villablanca, los lados mayores del patio están formados por una doble crujía. En las de la fachada, divididas en dos grandes espacios, con sus accesos correspondientes al patio y a la calle, aparecen, en el mayor las caballerizas y, en el pequeño, las habitaciones del capitán y las de un subalterno. En las crujías traseras del edificio, el dormitorio de la tropa ocupa una de ellas y la parte central de la que da al patio. En esta crujía y a los lados del dormitorio, aparecen los servicios y el cuarto del sargento, a un lado, y el cuarto del trompeta y la cocina, en el contrario. Los lados menores del patio son ocupados por la caballeriza, la cocina y los servicios de los oficiales, a la izquierda, y las cuadras para los caballos enfermos y un almacén para paja, a la derecha. En el de Cortegana, la fachada y los lados menores del patio presentan una doble crujía, mientras que la trasera del mismo sólo tiene una. En ésta se sitúan la caballeriza de la tropa y de los oficiales. El resto del edificio se encuentra distribuido en dos espacios en forma de "L", separados por un pasillo, al centro de la fachada, que comunica la calle con el patio interior. De estos espacios, el de la izquierda, es ocupado por las dependencias del veterinario, del subalterno y del capitán. Por el de la derecha, se distribuyen el dormitorio de la tropa, cocina, retrete y cuartos del sargento y del trompeta. El cuartel del Cerro del Andévalo presenta una planta casi cuadrada. Tras el vestíbulo y el cuerpo de guardia, se encuentran las cuadras, ocupando todo el ancho del patio, distribuyéndose en dos naves divididas por pilares cuadrados. El dormitorio de la tropa, organizado en dos dependencias con sus respectivos servicios y cocinas, ocupa parte de los frentes menores del patio. Cerrando el cuarto flanco de éste, se disponen las dependencias del sargento y del trompeta. Las habitaciones del resto de los oficiales, con sus cuadras y servicios, se sitúan flanqueando las cuadras y en la crujía de fachada.

En el último subgrupo de los edificios de una planta se incluyen los cuarteles de Villanueva de los Castillejos y Puebla de Guzmán, cuya principal novedad es presentar dos patios. En aquel, el acceso figura en uno de los lados menores, determinando un pasillo que atraviesa todo el edificio hasta finalizar en otra puerta hacia la calle. A su izquierda queda un patio cuadrado, cuyos tres lados están ocupados por el dormitorio de la tropa, la cocina, las letrinas y los cuartos del sargento, trompeta y del veterinario. El sector del edificio situado a la derecha del pasillo, tiene 


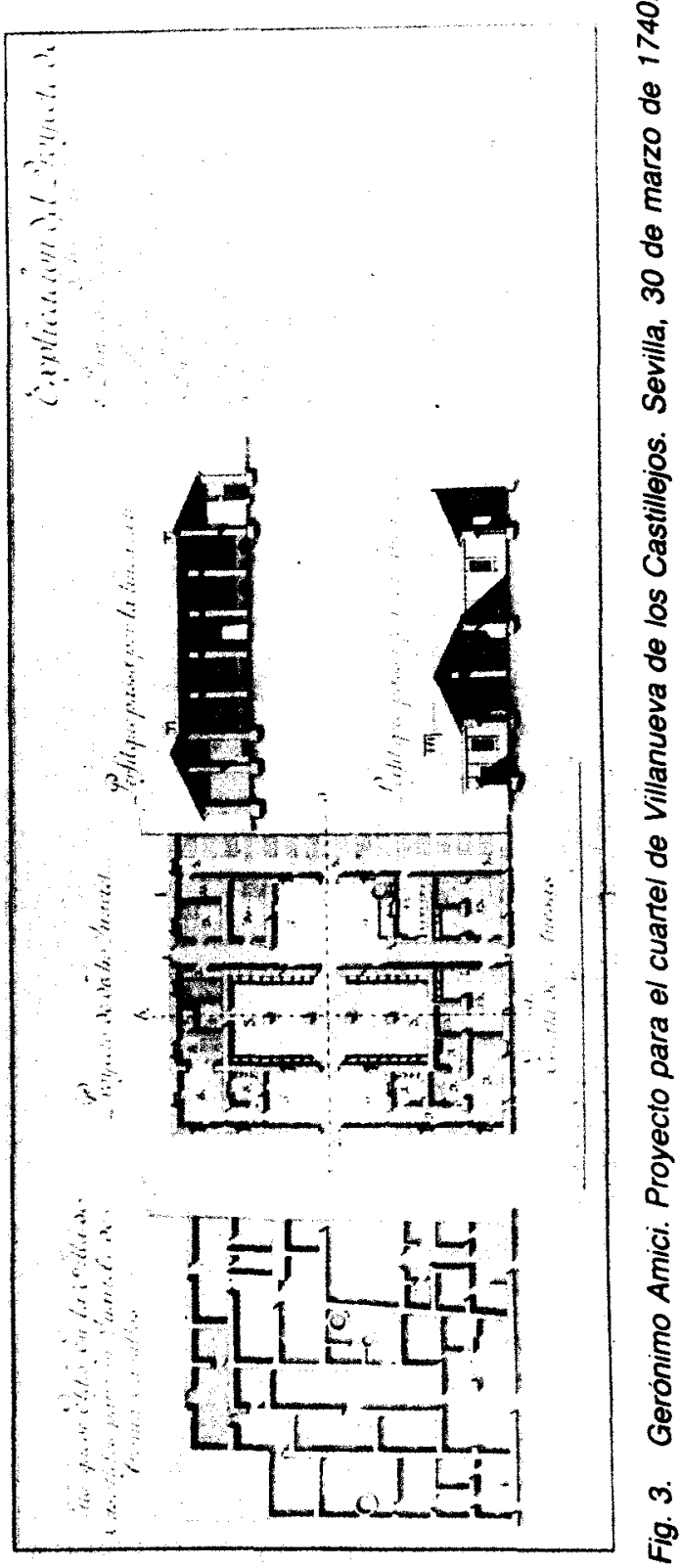




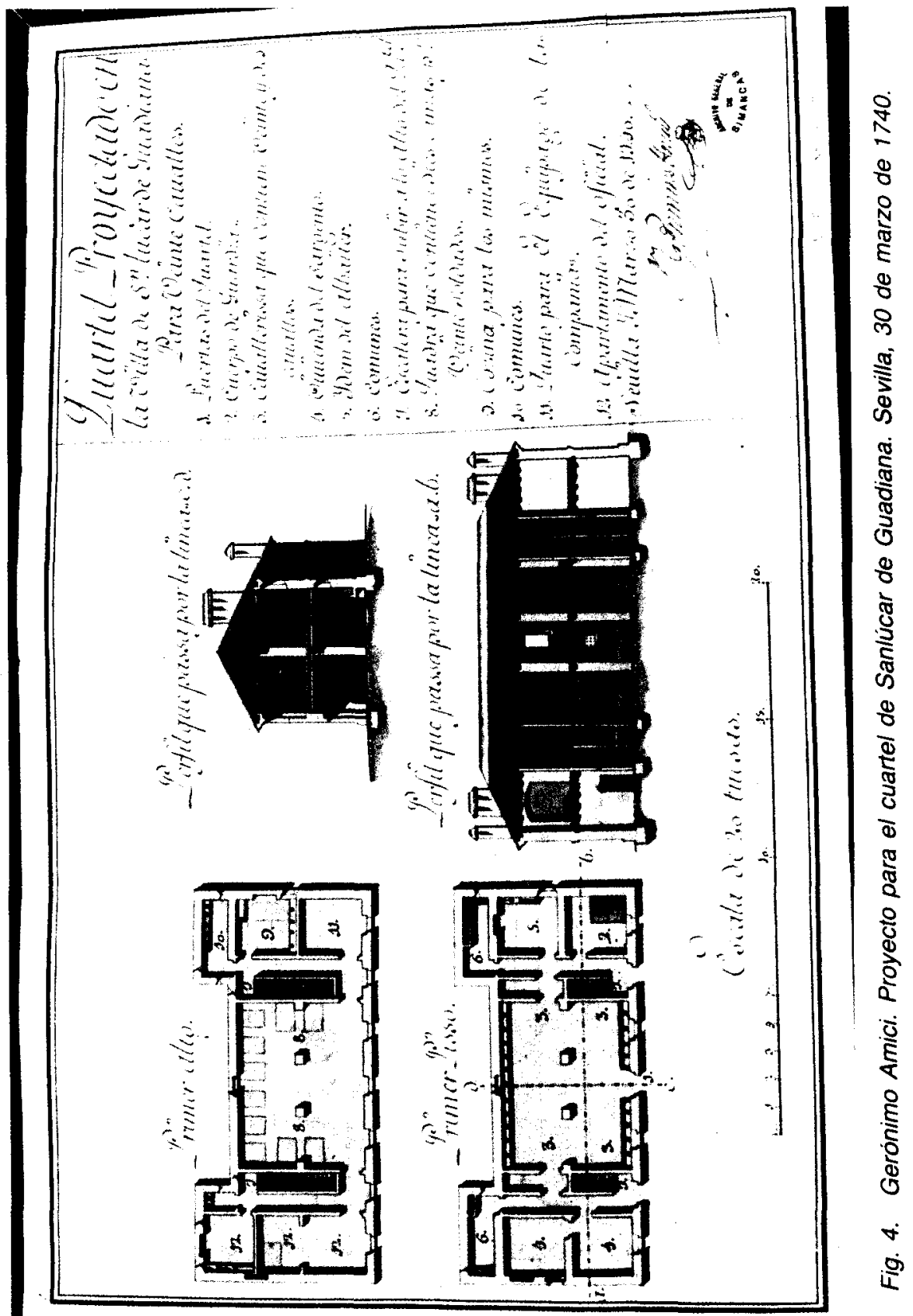


como elementos destacados un patio rectangular y las caballerizas, formadas por una doble nave separadas por pilares cuadrados y con acceso a ambos patios. Se completa el conjunto con las habitaciones del capitán y de un subalterno, cerrando el cuarto lado del patio un muro, con puerta a la calle.

El cuartel de Puebla de Guzmán presenta planta en forma de "U", siendo uno de sus brazos ligeramente más corto. El acceso se efectúa desde el estrecho patio intermedio, al que se abren por la derecha y fondo las cuadras para los caballos de los oficiales, el cuerpo de guardia, las caballerizas para la tropa, unos almacenes y las dependencias de un sargento. Por el frente izquierdo, se encuentran los dormitorios de la tropa, distribuidos en tres grandes salas comunicadas entre si, un corredor de conexión con un segundo patio y las dependencias de un sargento, el trompeta y un subalterno. Se completa la zona con un espacio cuadrado, con las dependencias del resto de oficiales. Tras este frente se sitúa el segundo patio, de planta rectangular y cerrado por muros.

El segundo grupo de cuarteles proyectados estaría formado por los edificios de planta rectangular con dos pisos. En un primer subgrupo se incluirían aquellos que no poseen patio, como los de Ayamonte y Sanlúcar del Guadiana. El cuartel de Ayamonte presenta dos grandes bloques sin conexión entre ellos. El piso bajo del primero, con planta cuadrada, to ocupan la casa del subalterno, la caballeriza de los oficiales, una dependencia para un criado y las escaleras. En el piso superior se encuentran los apartamentos del capitán y de un subalterno. En el espacio dedicado a la tropa, en planta baja, se hallan las cuadras, con acceso directo desde la calle, distribuidas en tres naves comunicadas entre si y con el corredor de la puerta principal. Al otro lado de dicho corredor se disponen las escaleras, el cuerpo de guardia, vivienda del sargento y del veterinario y unos almacenes. En la segunda planta, sobre las cuadras, se localiza el dormitorio, la cocina, y los cuartos del sargento y del trompeta. Los servicios, tanto de oficiales como de la tropa, se encuentran en las traseras del edificio en unas construcciones sobresalientes de la línea de muros. El proyecto de Sanlúcar resulta más sencillo que el anterior. Las cuadras, con acceso directo a la calle, ocupan el centro del edificio, estando divididas por pilares en dos naves. A cada lado de éstas se sitúan unas escaleras y las viviendas del sargento y la del veterinario con el cuerpo de guardia. En los ángulos del edificio, tras estas dependencias y sobresaliendo del mismo, se encuentran las letrinas. El piso superior presenta la misma disposición, ocupando la zona central los dormitorios de la tropa, y destinándose un flanco a la vivienda del oficial y el otro a los servicios, la cocina y almacén. 


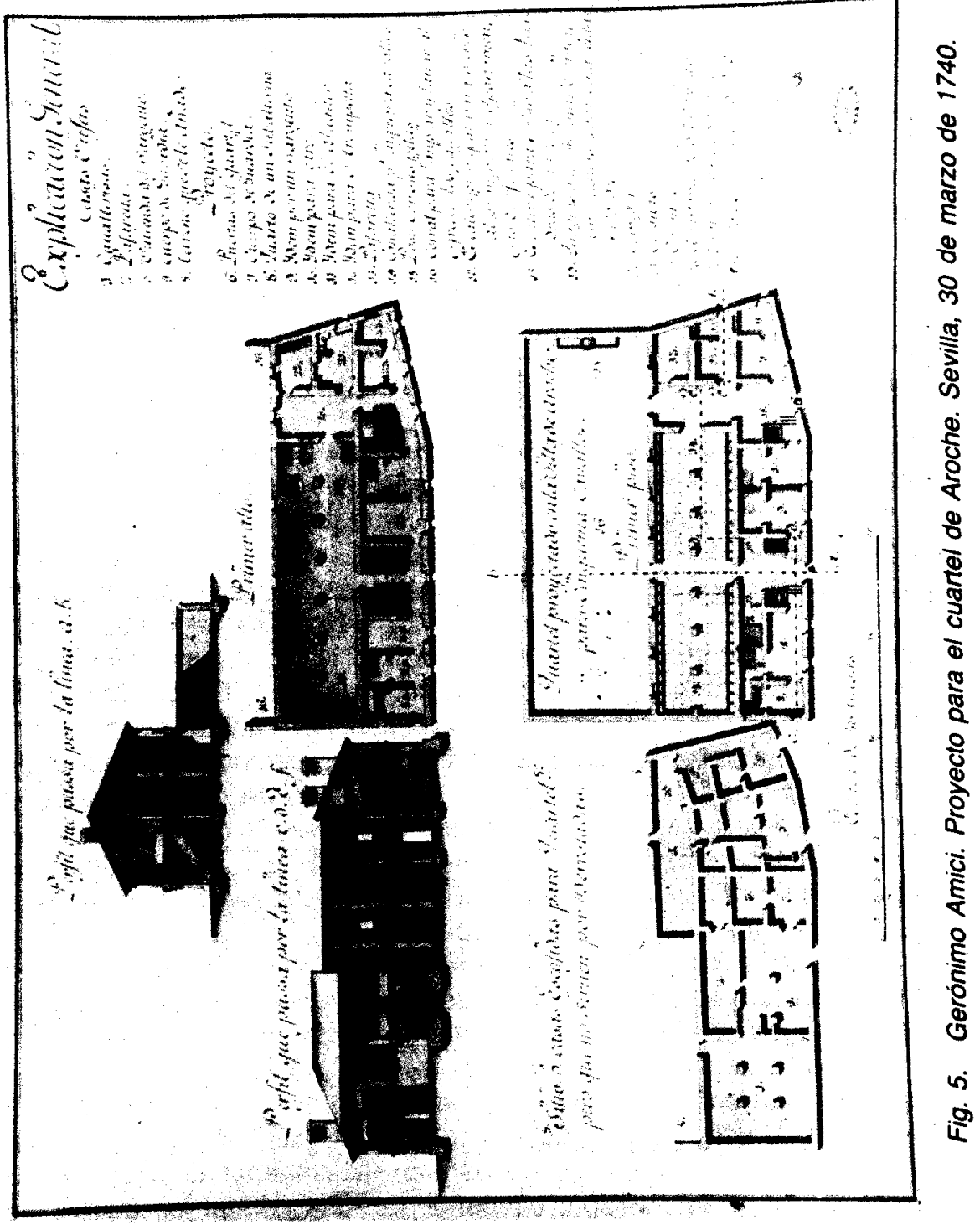




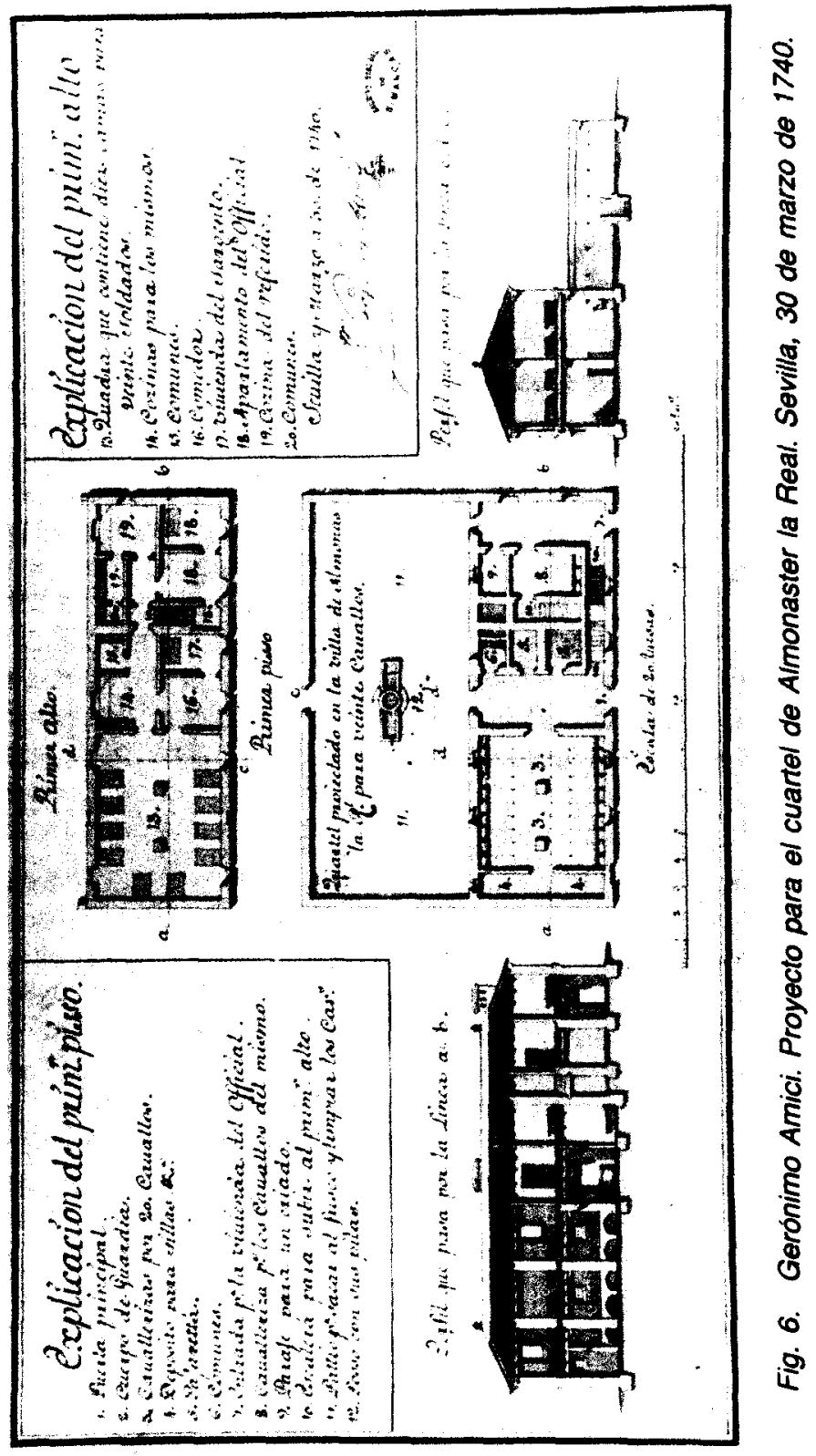


El subgrupo formado por los cuarteles de Lepe, Aroche, Almonaster y Trigueros, se caracteriza por tener tras el edificio un patio, que sólo en el caso de Lepe es utilizado en sus lados menores para vivienda de los oficiales. Siguen siendo de planta rectangular, colocándose las caballerizas de la tropa 0 al centro del edificio, o en uno de sus extremos. Éstas presentan dos naves, separadas por muros o, como en el caso de Almonaster y Aroche, por pilares. Los dormitorios de la tropa se siguen colocando sobre las cuadras. En los espacios sobrantes se colocan las restantes dependencias. Tienen dos accesos con escaleras separadas, una para oficiales y otra para la tropa, excepto en el de Lepe, con una sola entrada y escalera única y comunes a ambos grupos.

Un tercer conjunto de cuarteles podría formarse con los que presen$\tan$ características de los dos grupos anteriores, es decir, que presentan al mismo tiempo una y dos plantas. De los tres cuarteles que forman el grupo, Huelva, Cartaya y Encinasola, se estudian separados estos dos por construirse dentro de una antigua fortificación y presentar la misma disposición. El cuartel que corresponde a Huelva ofrece planta trapezoidal, ocupando las dos crujías de fachada las habitaciones para dos subalternos, el capitán, el cuerpo de guardia y los accesos al patio y a la segunda planta. En los tres lados restantes del patio se colocan las cuadras. La planta alta sólo existe en las dos crujías de fachada y en los lados menores del patio. En estos últimos se colocan los dormitorios de la tropa, repartidos en dos grandes salas. El resto del espacio de la planta alta está ocupado por la cocina, letrinas, dependencias de dos sargentos, el trompeta y varias habitaciones para vestuarios y almacenes.

Los cuarteles de Encinasola y Cartaya, a pesar de tener plantas distintas según la fortificación en la que se encuentran, presentan la misma distribución. Ambos se organizan alrededor del patio, al que se accede por uno de los lados menores desde la plaza de armas del recinto fortificado. El lado menor frontero al acceso, está ocupado por un edificio de dos plantas, sirviendo la segunda para residencia de los oficiales de mayor graduación. En este mismo edificio, en planta baja, se encuentran las cuadras de los caballos de los oficiales y diversas habitaciones para los encargados de la tropa y las cuadras. En los lados mayores del patio. en el de la derecha, se sitúan el dormitorio de la tropa y, a la izquierda, las caballerizas de esta. Ambos lados se completan con el cuerpo de guardia, cocinas y letrinas, almacenes y, en el caso de Encinasola, dependencias para dos sargentos.

Una excepción a los proyectos anteriores es el que corresponde a Moguer. Presenta planta casi rectangular, hallándose su único acceso en uno de los lados menores del edificio. En el mismo flanco se encuentra 


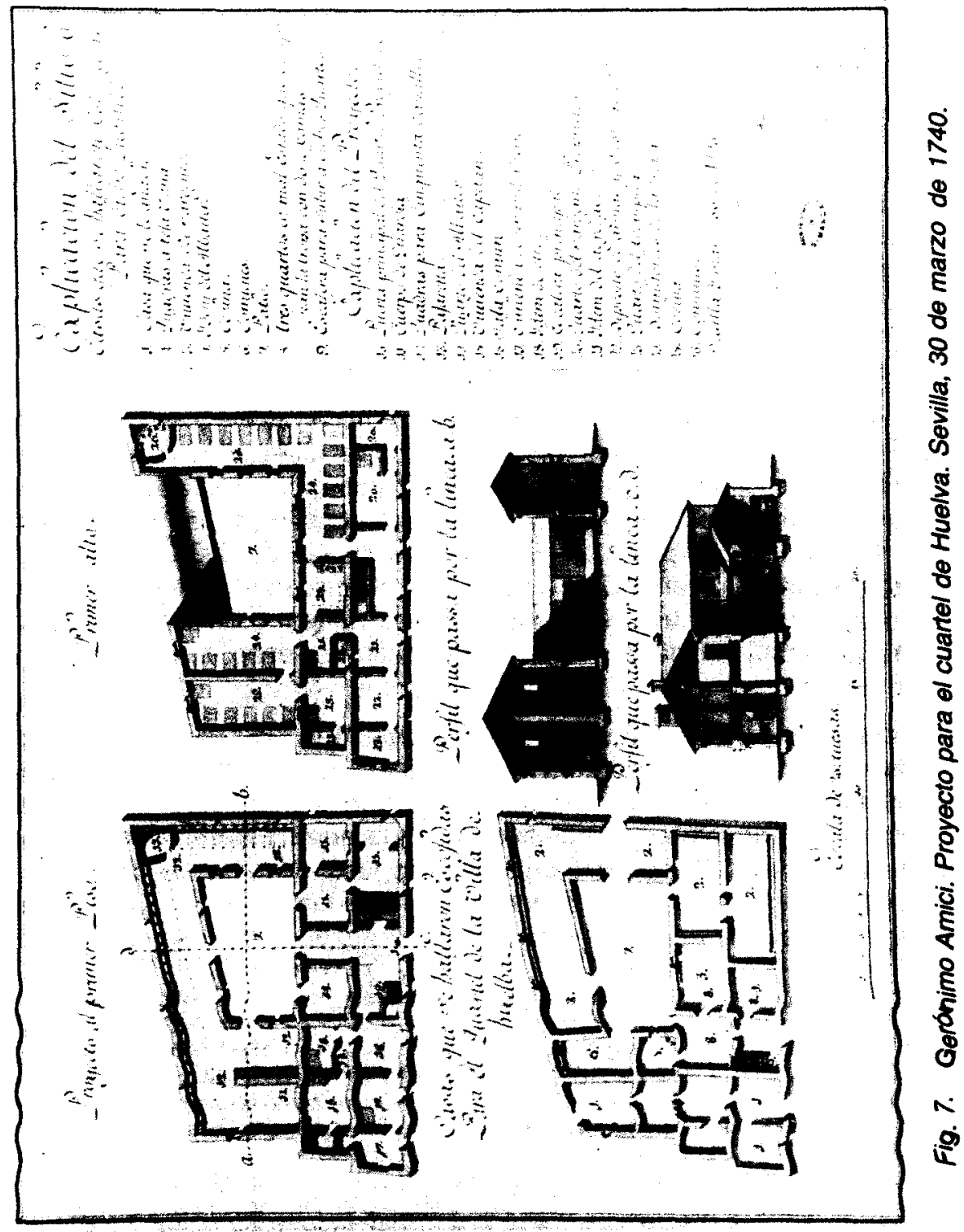


el cuerpo de guardia, cuarto para criados, una cochera, el acceso al patio y las escaleras para el primer y segundo piso. En estas plantas, se sitúan dos casas para oficiales de alto grado. Junto a estas dependencias, y siguiendo la línea de fachada, pero con solo dos plantas, se encuentran la casa del capellán, en la baja, y la del teniente, en la alta. El patio, cuadrado, presenta dos plantas en el lado derecho, con las dependencias de oficiales y ayudantes, $y$, en el frente izquierdo, un muro de cerramiento. El cuarto lado, frontero a la puerta de acceso, tiene cuatro crujias, convirtiéndose la última de éstas en un segundo patio. En éste sus extremos menores son ocupados, a un lado, por los servicios, en las dos plantas $y$, en el otro, la cuadra para caballos enfermos, on planta baja. Carece de planta alta. Las dos primeras crujias y parte de la tercera se dedica a cuadras, en planta baja, y a dormitorio de la tropa, en alta. El resto del edificio es compartimentado en dependencias para el trompeta, sargento y veterinario, en la planta baja, y cocina, letrinas, y cuarto para otro sargento, en la planta alta.

El 27 de febrero de 1734 es aprobado por el rey el establecimiento del «Regimiento de cavalleria provincial de la Costa de Andalucia, llamado de Cuantiosos». En su capítulo V, se especifica que además de los lugares donde ya estaba asentado ase agreguen, para más dotación del Regimiento, las ciudades de Ayamonte, y San Lúcar de Guadiana, y las demás Villas, y Lugares del Condado de Niebla, como también, que el reparto se haga distributivamente en ellas, $y$ en todo el Reynado de Sevilla, comprehendido el campo de Gibraltar, la plaza de Tarifa y la Villa de Puerto Reals ${ }^{13}$.

De dicho Regimiento, doce de sus compañías se asentaron en otras tantas localidades de la provincia de Huelva, con el fin de controlar la frontera luso-andaluza. En marzo de 1738, el Ingeniero Jefe Gerónimo Amici, con el encargo de reconocer el estado de tales establecimientos, se encontraba en la ciudad de Sevilla, después de haber efectuado una visita a la frontera ${ }^{14}$. La documentación de ese año que se ha localizado,

13 Archivo Municipal de Sevilla (A.M.S.), sec. 5.", esc. 1.: tomo 13, n. 2 , pág. 34.

14 Amici ya habría estado en otra ocasión en Sevilla. Cuando en 1724, se le pide a Jose Prospero Verboom que realice un informe sobre las obras que se deberían de realizar en el ro Guadalquivir a su paso por la ciudad, para ovitar las peribdicas inundaciones que padecía Sevilla. Para ello, presentará al Marqués de Castelar una relación con los ingenieros que le deberian acompanar en la visita a Sevilla. En dicha relación aparece el nombre de Gerónimo Amici, como ingeniero extraordinario. Dicho informe tue leído en el Cabildo celebrado el 27 de marzo de 1725. A.M.S., sec. 5.", esc. 1.", tomo 198, exp. 3. Para más información sobre Gerónimo Amici, véase CAPEL, Horacio et alli, Los ingenieros militares en Espana. Siglo xvII. Repertorio bibliografico $\theta$ inventario de su labor cientffica y espacial. Barcelona 1983, págs. 34-35. 


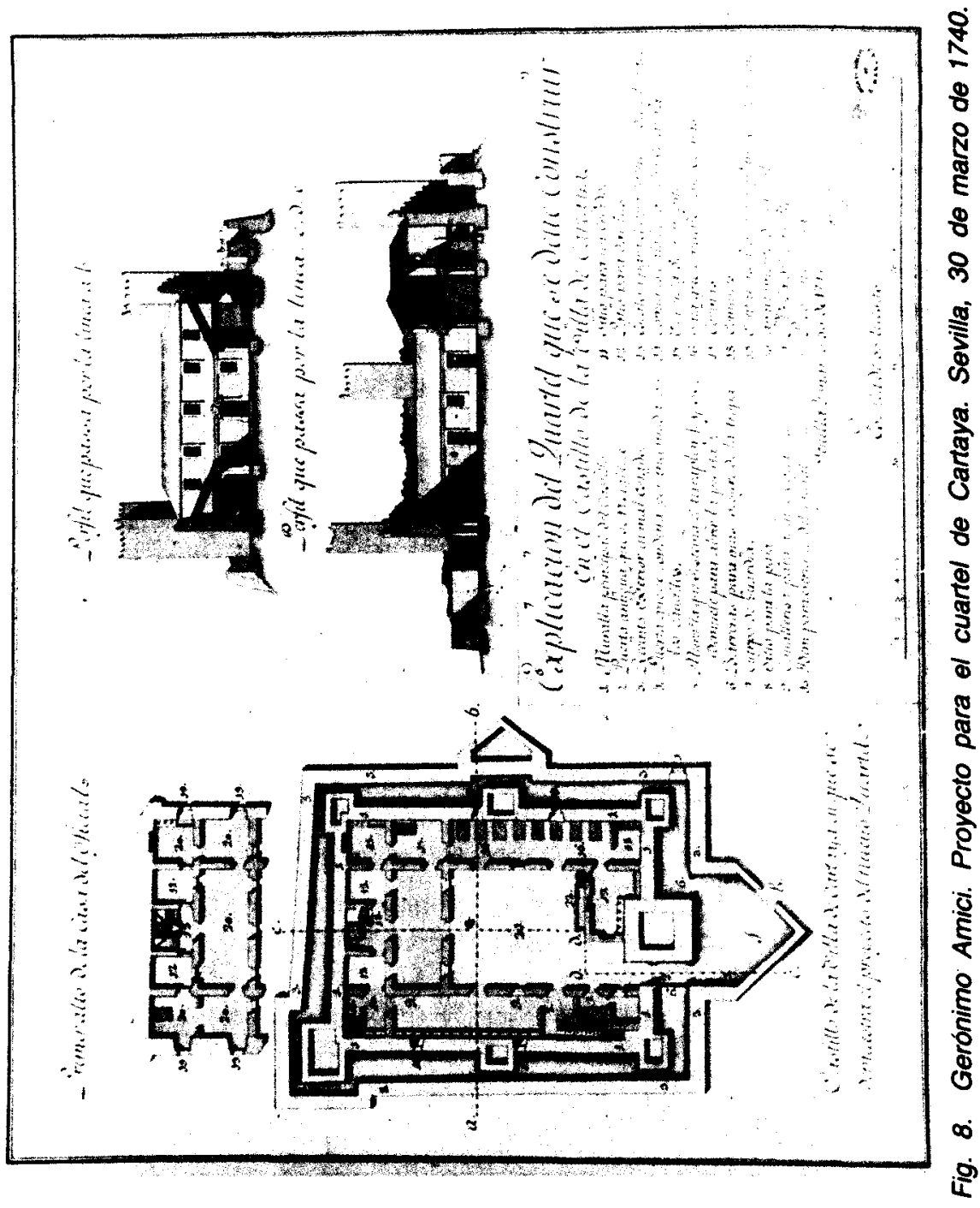




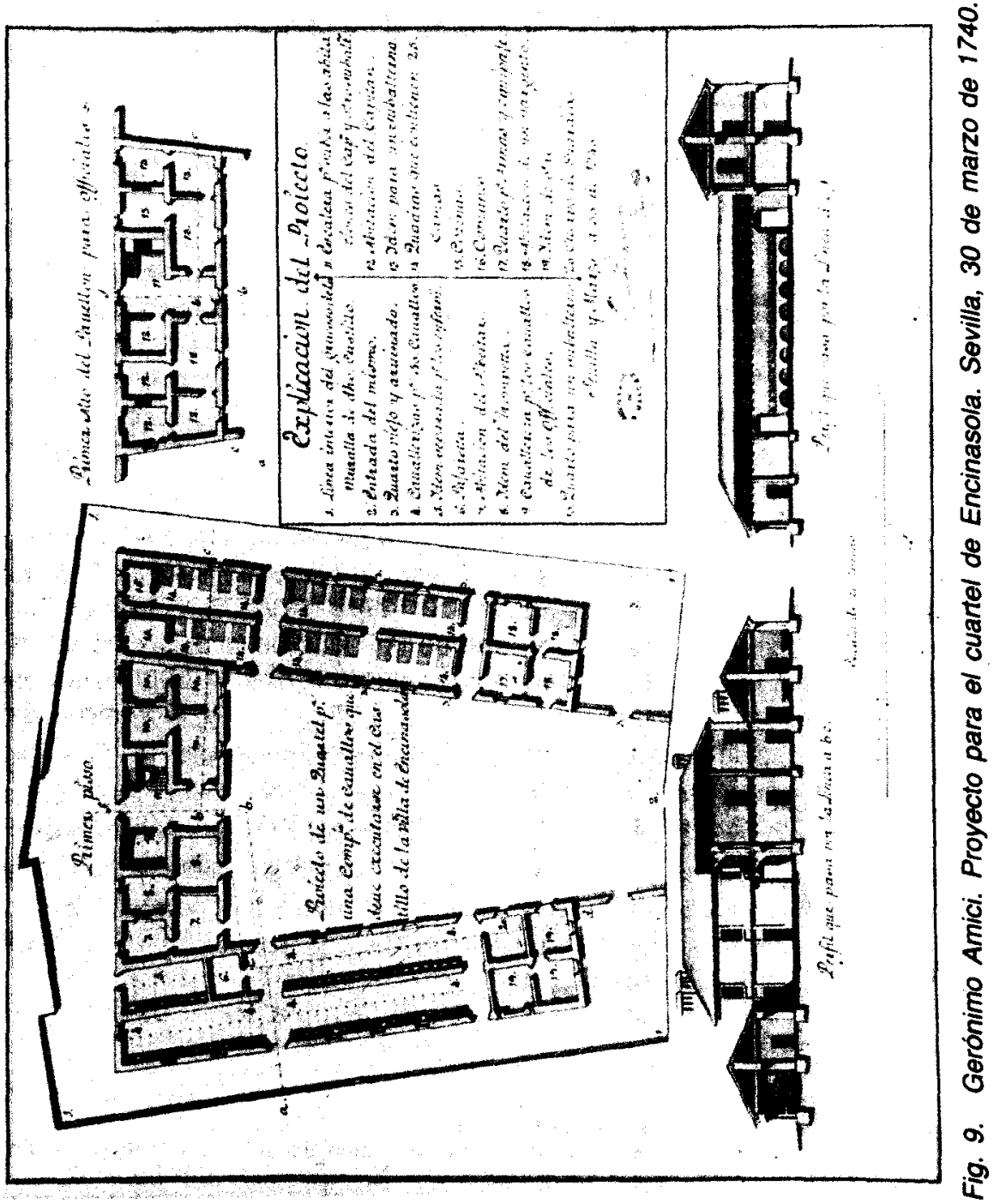


curiosamente, no se refiere al encargo del ingeniero, sino a los problemas que tuvo con el Cabildo Sevillano por motivo de su alojamiento en la ciudad ${ }^{15}$. Amici, tras el viaje por la provincia de Huelva, se instala en Sevilla en la «posada dela Reyna», para pasar más tarde, al «paraxe que supone el Cabildo para los oficiales subalternos, y otros que deven delinear los papeles que se deven remitir ala Cortex. Ninguno de los dos establecimientos le tuvo que resultar cómodo, pues, en ese mes, pide al Cabildo permiso para alquilar una casa a eFrancisco de Araoz que está en la calle de las Aguilas frente a las Monjas de Santa María de Jesús", ya que era el Concejo quien debía correr con los gastos ${ }^{16}$. Así lo recuerda una carta del rey, fechada en mayo del mismo año, en la que se ordenaba a la ciudad facilitase al ingeniero «el aloxamiento correspondiente, en una casa particular donde pueda travajar el tiempo que nezesiten ". El Cabildo no responderá a la petición de Amici y éste escribe una segunda carta en junio, pues la casa había sido «ajustada por un año que principia al próximo San Juan». Si bien, no conocemos la respuesta del Ayuntamiento, si es cierto que Amici ocupó la citada casa, por lo menos hasta junio de 1739 , no pudiéndose establecer su posterior permanencia en ella por faltar la documentación correspondiente.

El alquiler había sido estipulado en 2.450 reales de vellón, que se tenian que pagar por semestres adelantados. Para marzo de 1739, aún no se había realizado ningún pago, ni por parte de Amici, ni por el Cabildo. Por esta razón, Araoz, al no ponerse de acuerdo ninguna de las dos partes y sabiendo que el Ayuntamiento tenía designado 1.550 reales para el alojamiento de Amici, le pide dicha cantidad y que el resto, hasta completar el alquiler, se le retuviere al ingeniero de su sueldo. Pensamos que el problema queda zanjado cuando el 7 de julio, el rey ordena el alquiler de la casa de los «arbitrios aplicados a gastos de guerra».

De los documentos referentes al año 1739 , se deduce que Amici había mandado al Ministerio de la Guerra una serie de informes explicando la lamentable situación de la tropa en estos lugares, habiendo decidido repartir las doce compañias del regimiento en diecinueve localidades, y no en doce como estaba previsto originariamente. El 10 de octubre de

\footnotetext{
15 A.M.S., sec. 5., esc. $1 . \because$, tomo $13, n .^{\circ} 3$.

16 En otros documentos aparece el nombre de «Juan de Araoz, Jacome de Linden», en vez de Francisco de Araoz.

17 En dicha carta se especificaba que Amici estaba acompanado por dos ayudantes. De ellos, sólo se conoce que eran dos ingenieros con el cargo de extraordinarios. Posiblemente, uno de ellos sería «Mateo Bodopich", a quien se le ordena, of 27 de febrero de 1740, trasladarse a Ceuta, en el caso de que Amici, pudiera prescindir de él. A.G.S., G.M., leg. 3.673. Expediente del cuartel de Santa Bárbara.
} 
1739 se le comisiona para que, junto con Andrés Caballo, se volvieran a visitar los pueblos, eligiéndose las casas o lugares donde se deberian de construir los nuevos cuarteles y se redactaran los proyectos de los mismos ${ }^{18}$. Las visitas a las poblaciones se realizarán entre los meses de noviembre-diciembre de 1739 y febrero de 1740, terminándose los distintos proyectos en Sevilla el 4 de marzo de 1740, por lo que cabe considerar que la redacción de los mismos habia sido iniciada en fecha anterior a la comisión del 10 de octubre de 1739. De este periodo existen varias cartas entre Amici y el Duque de Montemar, en las que da cuenta de los problemas que va encontrando al visitar las poblaciones ${ }^{19}$. La primera de ella se fecha en Ayamonte el 1 de enero de 1740, pero hace referencia a otra anterior escrita en Huelva el 6 de diciembre. La última de las cartas está redactada en Santa Bárbara el 15 de febrero y en ella se especifica que el 16 sale para Aroche, faltándole por visitar Cortegana, Almonaster, Encinasola y El Cerro ${ }^{20}$.

Las doce compañias quedarian distribuidas formando una doble línea de defensa. La primera, compuesta por cuatro compañias y diez hombres más, se distribuía desde Ayamonte hasta Santa Bárbara de las Casas, vigilando el río Guadiana. La segunda reforzaría a la anterior con cuatro compañias y cuarenta hombres, que junto con los diez anteriores forman una quinta compañia, controlando la Sierra Norte y los afluentes del Guadiana, desde Encinasola hasta Trigueros. Al mismo tiempo, se procuraba el reforzamiento de la vigilancia del mar, desde Moguer hasta Ayamonte, con tres compañias. En cuanto a los caballos que componian cada cuartel, estos fueron distribuidos atendiendo a los emplazamientos estratégicos y a la mejor defensa de la ciudad de Sevilla ${ }^{21}$.

1s A.G.S., G.M., leg. 3.673, exp. del proyecto de cuertel para la villa de Moguer. En realidad, las visitas tendrian que ser efectuadas con el Comisario General, Fernando de Montes, pero al hallarse enfermo es sustituido por Andrés Caballo.

19 A.G.S., G.M., log. 3673, exp. de los proyectos de cuerteles para las poblaciones de Ayamonte, Castillejo, Paymogo y Santa Bárbara.

20 El recorrido realizedo por Amici coincide con el número de orden dado a los distintos proyectos, excepto el referente a Trigueros, que con el número diecinueve, habria sido visitado antes que Moguer y Huelva, según se deduce de la carta fechada en Santa Bárbara el 15 de febrero.

${ }_{21}$ Gerónimo Amici, en su carta de 27 de enero de 1740, propone un cambio en la distribución de cuarteles con objeto de defender mejor la entrada al río, propuesta que no debió ser aceptada. En ésta se aludía a la salida de diez hombres del cuartel de Huelva, que cambiarian periódicamente, para instalarse en el paraje de Aljaraque, con vistas a una mojor defensa de la desembocadura del rio Odiel. La Redondela, por lo cercano a Ayamonte, pasaría a tener sólo 10 caballos, los cinco que se le quitaban se unirian a Cartaya para que ésta igualara con Lepe en 20 caballos. De los 50 soldados de Ayamonte, de seis a ocho pasarian a la zona conocida como el Dique, «a 1/2 legua de Ayamontew, para contro- 
Los cuarteles serian construidos por los propios vecinos, que debian de proponer los arbitrios para su construcción. Además, todos ellos se habían comprometido a ceder el solar necesario y a facilitar el acarreo y transporte de los materiales, asi como a efectuar las demoliciones de estructuras que no sirvieran, a la excavación de los cimientos y a aportar y cortar de sus bosques la madera precisa. La mayoría de los arbitrios elegidos eran los pertenecientes al fruto de la bellota, completándose en algunas localidades con las rentas que pudieran proporcionar las dehesas comunales.

A pesar de que los Cabildos se celebraron entre noviembre de 1739 y marzo de 1740, a fines de octubre de ese año aún no se habia comenzado la construcción de los cuarteles. El Intendente de Andalucia, junto con el Duque de Montemar, se quejan a Amici de la escasez del dinero a entregar por los pueblos. En contestación, Amici alude a las medidas a aplicar directamente por el Ministro de Guerra y el Intendente, ya que de llevarlas a cabo alos justicias» de los pueblos, no tendrían resultado. Además de las ya mencionadas del transporte de los materiales y las demoliciones y excavaciones, cada población debería cortar la madera a fines de este año. Se embargarían las tejas, ladrillos, guijarros, arena y cal que se encontraran en las villas respectivas y en los hornos de los alrededores. Estos materiales se devolverían en especie o en dinero por cada localidad a sus propietarios, una vez concluidas las obras. Se pondrian a disposición de los cuarteles los arbitrios de 30 nuevas poblaciones situadas en los alrededores ${ }^{22}$. Por último, se haría $\alpha$ el repartimiento de paja y utensilios», entre las 49 poblaciones. Éstas deberian prestar una porción de utodos aquellos positos que confesaron los justicias en

\footnotetext{
lar la entrada al rio Guadiana y se tumarian períodicamente con el resto de la guamición. Villablanca quedaría con 30 caballos, pasando los 10 restantes a depender del cuartel de San Silvestre, pero asentados en El Granado, población que habla pedido un destacamento, dando todas las facilidades para la construcción de un cuartel. Por tanto, la distribución de las companilas quedaría de la siguiente forma: Los cuarteles de Moguer, Huelva, Ayamonte, Encinasola, Aroche y Trigueros estarian formados por 50 caballos; los del Cerro y villablanca contarían con 40 caballos. Tendría 35 el de Puebla de Guzman; 30 los de villanueva y Cortegana; 20 los de Lepe, Sanlucar del Guadiana y Almonaster; 15 en Cartaya, La Redondela y Paimogo. Por último, contarían con 10 cabalios los cuarteles de San Silvestre de Guzmán y Santa Bárbara de las Casas.

2 Estas poblaciones serian «Bodonal, Frejenal, Higuera la Real o de Fregenal, las tres Cumbres, la alta, la del medio y la baja, La Nava, Galarosa, Santo (o Saulo), Castano, Fuenteridos, Alajar, Santa Ana, Cabeza Rubia, Calaña, Las Cruces, Alonso, San Bartolome, Almadén, Granado, Alcarejo, Aracena, Salamea la Real, Berrocal, Valverde del Camino, Veas, San Juan del Puerto, Niebla, Villarosa, La Palma, Villalba, Manzanilla, Bollullos del Camino y Almontex. Carta de Gerónimo Amici fechade en Madrid, el 26 de octubre de 1740. A.G.S., G.M., leg. 3673. Expediente del proyecto de cuartel de la población de Castillejos.
} 
sus testimonios", y serían reintegradas, al terminarse las obras, de los propios arbitrios del pueblo del que se sacó ${ }^{23}$.

En dicho informe, también se dan algunos consejos sobre la dirección de las obras, ya que éstas no podrían realizarlas personas del pueblo, por su poca inteligencia y porque "con poco quieran hazer mucho para salir de las Jornadas". La dirección de obra la llevaría conjuntamente un Ingeniero y una persona designada por el Intendente. La vigilancia de las mismas sería encargada a los oficiales o sargentos de las distintas compañias y a cinco ingenieros. Uno de éstos se encargaria de las construcciones en Moguer, Trigueros y Huelva, otro de las de Cartaya, Lepe, La Redondela, Ayamonte y Villablanca. A un tercero le corresponderían las de Sanlúcar, San Silvestre, Castillejo y Puebla de Guzmán. A un cuarto las de Paimogo, Santa Bárbara y El Cerro. Por último, el quinto se haria cargo de las de Almonaster, Cortegana, Aroche y Encinasola. A éstos se les pagaría una mensualidad de los fondos destinados a los cuarteles y cada pueblo le proporcionaría el "aloxamiento y raciones". Como complemento a todos ellos, se contrataria a un aparejador, que cada quince días tendria que visitar las obras "con los planos" para comprobar su desarrollo y dar los consejos oportunos. Esta persona, además, tendría el encargo de informar al Duque de Montemar del estado de las obras periódicamente ${ }^{24}$.

No se ha localizado documentación alguna que ponga de manifiesto que los citados cuarteles se llegaran a realizar. Posiblemente, la magnitud del proyecto, la deficiente dotación de los vecinos y los nuevos gastos y necesidades ocasionados por el inicio de la guerra con Inglaterra, hicieron que ninguno de los cuarteles, si se comenzó su construcción, fuese terminado ${ }^{25}$. En el reconocimiento realizado por el ingeniero extraordinario Mauricio Rodríguez de Berlanga, en 1796 de las poblaciones de Ayamonte, Sanlúcar de Guadiana, Puebla de Guzmán y Paimogo, sólo se menciona que la defensa de estos pueblos estaba formada por los asentamientos de artilleria y los propios vecinos ${ }^{26}$. En el caso de Puebla de Guzmán se especifica, que no se habia dotado de Artillería

23 Jem.

24 Idem.

2s “Año 1740... La guerra con Inglaterra, que se havia publicado en Madrid el Diciembre de el año antecedente, se publico a qui (en Sevilla) con igual solemnidad, y grandes concessiones á los que armassen Baxeles, que anduviessen á corso contra aquel Reyno". Zúniga, Lorenzo de, Annales Eclesiasticos i Seglares de la Muy Noble, Muy llustre y Muy Leal Ciudad de Sevilla que comprehenden la Olimpiada, o Lustro de la Corte en ella. Sevilla, s/a, (1748).

26 Servicio Histórico Militar. Sec. A, vol. II. 
pero si de fusiles, que junto a los vecinos y "ayudado de algunos destacamentos de Ynfanteria y Cavalleria, podra defender mui bien sus hogares", lo que hace suponer que dichos destacamentos no se encontraban en la citada población. Tampoco Madoz menciona ningún acuartelamiento de caballeria en estas poblaciones. Sin embargo, señala la existencia de artillería en Sanlúcar del Guadiana y de "295 carabineros» como protección de la villa de Huelva ${ }^{27}$.

Como conclusión se puede afirmar que por circunstancia desconocidas, aunque relacionadas con las antes citadas, los diecinueve cuarteles proyectados por el ingeniero militar Gerónimo Amici, para el Regimiento de "Quantiosos" de Andalucia en la provincia de Huelva, no llegaron a construirse. Éstos, como otras muchas iniciativas del Cuerpo de Ingenieros Militares quedaron en simples proyectos. Sin embargo, se puede afirmar que dichos cuarteles son reflejo de las inquietudes y problemática de la arquitectura militar española del siglo XVIII.

27 Madoz, Pascual, Diccionario Geográfico-estadistico-histórico de España y sus posesiones en uitramar. Madrid 1845-50. Edic. Fac. Valladolid 1986. 
